\title{
Commentary: Hammers and nails
}

\author{
Dawn S. Hui, MD, and John H. Calhoon, MD
}

Venturini and colleagues ${ }^{1}$ nicely demonstrate what may prove to be a cleaner technique of providing antegrade cerebral blood flow during arch operations. The AV Flow cannula uses the Seldinger technique and a balloon-occludable tip, which provides nice inflow without need for a vesselencircling tape. It appears to have several exit holes to decrease the chance of the catheter exit being obstructed by the vessel wall. The novelty of this device is guidewire introduction using the Seldinger technique, the elimination of the need to stop flow to a head or neck vessel while constructing an anastomosis, and thus provide continuous flow. This allows for the AV Flow cannula to presumably improve cerebral protection throughout the hypothermic circulatory arrest time. It should ease arch vessel reimplantation or direct arch work, as a cannula in the anastomotic site is eliminated. The downside is the chance of causing a dissection or slim chance of misplacing a cannula outside the vessel lumen or even outside the wall. Similarly, it does leave one more site to dry up and a small concern for the creation of cannulation-site stricture. One other downside is simply that of space. The cannulation site takes up some length on the vessel to be reimplanted, and this must be a consideration. To me, in cases of aneurysm, it seems to offer an advantage because of the low risk and theoretical benefit. In the end, I am not sure the theoretical advantages are worth the additional lines and rigor required to place 2 or 3 of these in a case in which the temperature already adds likely ample protection to our current practice of sequential direct cannulation and anastomosis.

It is important to point out that this is not something envisioned for use in dissected great vessels, and one should

\footnotetext{
From the Department of Cardiothoracic Surgery, University of Texas Health Science Center at San Antonio, San Antonio, Tex.

Disclosures: The authors reported no conflicts of interest.

The Journal policy requires editors and reviewers to disclose conflicts of interest and to decline handling or reviewing manuscripts for which they may have a conflict of interest. The editors and reviewers of this article have no conflicts of interest.

Received for publication Aug 17, 2020; revisions received Aug 17, 2020; accepted for publication Aug 21, 2020; available ahead of print Sept 2, 2020.

Address for reprints: John H. Calhoon, MD, CT Surgery Department, 7703 Floyd Curl Dr, Suite 211L, San Antonio, TX 78229 (E-mail: calhoon@uthscsa.edu). JTCVS Techniques 2020;4:16

2666-2507

Copyright $(2020$ The Authors. Published by Elsevier Inc. on behalf of The American Association for Thoracic Surgery. This is an open access article under the CC BY-NCND license (http://creativecommons.org/licenses/by-nc-nd/4.0/).

https://doi.org/10.1016/j.xjtc.2020.08.051
}

not make such a leap of faith to consider use in that clinical picture. One other potential downside is the slim, but not remote, chance of dissection, which could be caused by a balloon-inflation injury. We have no way of knowing what that chance is in comparison with dissection of a vessel from encircling it and snaring it as we currently do. Other limitations would be vessels that are fragile although not dissected, or those with atherosclerotic burden, particularly on the anterior vessel wall. Finally, there is some difference in the flexibility of this technique. For example, once the arch is opened, the Seldinger technique would not be as safe as direct cannulation.

In the end, a good shop has lots of hammers for lots of nails, and this is a particularly interesting tool for the occasional job for which experienced surgeons will preferentially select it over any other.

\section{Reference}

1. Venturini A, Gallingani A, Asta A, Cannarella AM, Zanchettin C, Zoffoli G, et al. A new cannula for antegrade selective cerebral perfusion. J Thorac Cardiovasc Surg Tech. 2020;4:10-3. 